\title{
Why Secondary Towns Can Be Important for Poverty Reduction - A Migrant Perspective
}

\author{
Pre-print version, December $2017^{1}$ \\ Bert Ingelaere $^{2}$, Luc Christiaensen ${ }^{3}$, Joachim De Weerdt ${ }^{4}$, Ravi Kanbur ${ }^{5}$
}

\begin{abstract}
$^{6}$
This paper develops the concept of 'action space' as the range of possible destinations a migrant can realistically move to at a given point in time and, intimately linked to this, the set of possible livelihoods at destination. We show how this space expands and contracts over time through "cumulative causation". Such a dynamic framework allows us to appreciate the role of secondary towns in rural-urban migration and poverty reduction. Secondary towns occupy a unique middle ground between semi-subsistence agriculture and the capitalistic city; between what is close-by and familiar and what is much further away and unknown. By opening up the horizons of the (poorer) rural population and facilitating navigation of the nonfarm economy, secondary towns allow a broader base of the poor population to become physically, economically and socially mobile. Secondary towns therefore have great potential as vehicles for inclusive growth and poverty reduction in urbanizing developing countries. These are the insights emerging from in-depth life history accounts of 75 purposively selected rural-urban migrants from rural Kagera, in Tanzania.
\end{abstract}

Keywords: Migration, Urbanization, Secondary town, Off-farm employment, Poverty, Life history, Tanzania, Sub-Saharan Africa

\footnotetext{
${ }^{1}$ Final version available at :

https://www.sciencedirect.com/science/article/pii/S0305750X17304187?_rdoc=1\&_fmt=high\&_origin=gateway\&_docanchor=\&md5=b842 9449ccfc9c30159a5f9aeaa92ffb

${ }^{2}$ University of Antwerp, bert.ingelaere@uantwerpen.be

${ }^{3}$ Jobs Group of the World Bank Group, lchristiaensen@worldbank.org

${ }^{4}$ University of Antwerp and Catholic University of Leuven, joachim.deweerdt@uantwerpen.be

${ }^{5}$ Cornell University, sk145@ cornell.edu

${ }^{6}$ The authors would very much like to thank the migrant survey participants for sharing their life histories, the Tanzanian research assistants as well as two anonymous reviewers. Financial support from the Strategic Research Program of the World Bank Group and the International Growth Center of the Department of International Development, UK is further gratefully acknowledged. The findings, interpretations, and conclusions expressed in this paper are entirely those of the authors. They do not necessarily represent the views of the International Bank for Reconstruction and Development/World Bank and its affiliated organizations, or those of the Executive Directors of the World Bank or the governments they represent.
} 


\section{Introduction}

Urbanization and development go hand in hand (World Bank, 2009). Yet, the debate about urbanization and development is usually held in the aggregate, focused on economic growth as opposed to poverty reduction, and without differentiation of the urban space. Incipient evidence from Africa (Dorosh and Thurlow, 2013, 2014; Christiaensen and Todo, 2014) and South Asia (Gibson et al., 2017; Emran and Shilpi, 2017) suggests however that it is secondary town development that has especially great potential for poverty reduction, and possibly more so than advancement of cities.

Given the concentration of the poor in rural areas - 80 percent of the worlds' extreme poor live in rural areas (World Bank, 2016) - this may not surprise. Secondary towns offer offfarm employment opportunities nearby, thereby facilitating rural livelihood diversification, which has long been proven to be an important vehicle out of poverty (Ellis, 1998). Yet, cities hold the potential of larger economies of agglomeration and thus faster economic growth and off-farm job creation (World Bank, 2009). ${ }^{7}$

Taking an economic perspective, Christiaensen and Kanbur (2017) provide an initial review of the incipient theoretical and empirical literature on the reasons why secondary town development ${ }^{8}$ may be more poverty reducing than city development. Yet, many puzzling facts remain and the mechanisms behind them are still poorly understood. This is well illustrated by the findings from the Kagera Health and Development Survey (KHDS). This is a rather unique long running panel, which first interviewed a representative sample of about 915 households from rural Kagera, Tanzania in 1991. All household members, including those who moved to settle elsewhere, in other rural areas, secondary towns or cities, were subsequently interviewed again in $2010 .^{9}$

As shown by Beegle, Dercon and De Weerdt (2011), those who left their baseline locations clearly fared much better than similar individuals who didn't move. Christiaensen, De Weerdt, and Todo (2013) further find that moves to cities (in this case Dar es Salaam and Mwanza, the two largest cities in Tanzania) were substantially more lucrative than moves to secondary towns. Yet, despite the larger gains from moves to the city, more than twice as

\footnotetext{
${ }^{7}$ Henderson and Becker (2000), however, argue that urban primacy — a predominance of the largest city in the urban system-is often also driven by political motivations, not just economic forces, with the resulting congestion hampering their growth prospects and those of their surrounding hinterlands.

${ }^{8}$ The channels through which small towns contribute to growth and poverty reduction include rural-urban (circular) migration and the diversification of livelihoods, the provision of services, the localized development of markets, as well as the increase of agricultural production of nearby rural populations (Baker 1990; Lanjouw et al 2001; Sattherwaite \& Tacoli, 2003; Owusu 2008; Taccoli \& Mabala 2010; Bryceson 2011).

${ }^{9}$ See De Weerdt et al. (2012) for a detailed description of the data and data collection process.
} 
many people moved to towns than to the city. As a result, migration to secondary towns contributed much more to overall income growth and poverty reduction in Kagera during the period under study (43 and 38 percent respectively) than migration to the cities (28 and 21 percent), at least in an accounting sense. ${ }^{10}$

It begs the question why and how many more migrants ended up in secondary towns despite more modest income gains. With the majority of the poor concentrated in rural areas, addressing this question also helps understand why development of secondary towns may hold greater poverty reducing potential than development of cities. So, what induces ruralurban migration, in general, and migration to secondary towns compared to large cities, in particular? Do these different urban environments attract different migrants, as emphasized by Young (2013)? Or, do they attract migrants with similar characteristics for different reasons (such as proximity favoring towns as it reduces the cost of migration) or through different processes (such as migration networks that arose due to historical idiosyncracies and help overcome the transport and search costs that rise with distance)?

To address these questions, a qualitative, life history approach is pursued. This helps obtain a more contextualized and path dependent understanding of the factors shaping migration and location decisions. ${ }^{11}$ In particular, in 2015, the study revisited 75 purposively sampled, young adult migrants from the original KHDS and recorded their life histories with a focus on their migration trajectories and the factors motivating them. While all migrants originated from the same region, with similar rural socio-economic backgrounds, they literally followed quite different paths in life: some made only one move, while others moved up to 9 nine times; some migrated to secondary towns, some ended up in mega-cities, like Dar es Salaam, while still others eventually returned to their village after migrating. This richness in experiences provides a good setting to uncover migration patterns and the factors shaping them.

Through the analysis of the migrant narratives two important concepts emerge: 1) the notion of a migrant's action space; and 2) the notion of cumulative causation. The first refers to the set of plausible destinations and livelihoods a prospective migrant can each time reach (in a single move). It relates to both physical as well as socio-economic mobility. The second concept, cumulative causation, refers to the path-dependent, sequential nature of migration, during which factors that enable or hinder mobility - such as financial resources, networks,

\footnotetext{
${ }^{10}$ The results abstract from feedback effects between cities and towns, as well as self-selection (Young, 2013).

${ }^{11}$ The literature probing migration processes is longstanding, both through quantitative and qualitative inquiry. Yet, much of it has focused on international migration and the studies examining internal migration often conceptualize the urban space as unitary and monolithic. A notable exception in the quantitative tradition is Fafchamps and Shilpi (2012), who, building on insights from economic theory, apply econometric techniques to study the determinants of the choice of migration destination in Nepal (conditional on migration).
} 
aspirations and norms - are each time gradually reshaped, thereby altering the migrant's action space. Migration emerges as a cumulative process through which each migration decision (and destination) taken, affects the basis for taking the next decision (destination). This contrasts with a more common conceptualization of migration as a one-shot event, in economic modeling and policymaking.

It also bears on the importance of secondary towns in facilitating migration. While the migrants in our study widely consider the capital city to offer most opportunities by far, it is, originally, within the action space of few. The first move is therefore special. At that point, the focus is on getting out of agriculture and the village (which migrants often consider not to provide much perspective), to shake things up and open doors, including, but not only, to more desirable migration outcomes later on. As a result, the first move is more often towards a secondary town, which, given its proximity, is more likely to fall within the original action space. For many it also turns out to be where they end up, as the window of opportunity for further migration usually also narrows when families are started and people settle down in their jobs.

In sum, many people migrating out of agriculture end up in secondary towns because they can, and remain or return to secondary towns because they have to, due to the binding nature of life and livelihood choices and events. Other study participants end up in secondary towns because they want to. They seek to live in an urban environment and the secondary town satisfies their needs. They do not aspire to move further towards big cities. While seeing migration and location choices as the outcome of a deliberation process weighing opportunities and costs in the broadest sense is not new (Lall, Selod, Shalizi, 2006), its dynamic, iterative nature and the powerful role secondary towns can play in the process, as important entry points to livelihood diversification and poverty reduction, has remained underappreciated.

The role of secondary towns in facilitating migration is also better understood when considered within migrants' own conception of the urban space. A first defining feature of the urban space, revealed through the conversations, is 'mzunguko wa pesa'. It literally translates from Swahili as 'the circulation of money', but is often invoked to convey the broader notion of vibrancy, in terms of circulation of money, goods, people, ideas and so forth. Respondents set urban areas apart from rural ones in terms of this metric, with bigger cities (e.g. Dar, Mwanza) considered more vibrant, and thus more attractive, and secondary towns holding the middle ground between the village and the city. A second distinguishing 
feature is the monetary nature of exchange in urban areas, which contrasts with the more reciprocal nature of life in the village and is often considered a challenge, especially the first time around. Finally, urban areas are characterised as anonymous, providing opportunities to escape from the more stifling village environment. Yet, the lack of a tight social networks is also considered an obstacle, as one now needs to learn how to operate within that anonymity, with limited safety nets. In sum, while cities speak most to the imagination, secondary towns are mentioned to be "far enough, but not too far". They occupy a more manageable position in between the more reciprocal livelihood of the village and the capitalist economy of big cities.

The paper proceeds as follows. Section 2 briefly discusses the life history approach and reviews the key features of the data collection. This is followed by a recount of the history of Raymond, one of the study participants, bringing the deep dynamic nature and complexity of migration to life (Section 3). Section 4 develops the notions of action space and cumulative causation. Section 5 lays out how migrants consider different locations along the rural-urban spectrum, followed by an in-depth analysis of the factors that shape a migrant's action space in section 6. Section 7 then revisits the motivating question of the paper, i.e. why many more migrants of Kagera end up in secondary towns, despite larger gains from moves to the city? Section 8 concludes.

\section{The Life History Approach in Practice}

As a dynamic process that connects several locations over time as well as important 'turning points' in people's lives (Bakewell \& Bonfiglio 2013: 5), migration is best understood through a life course approach. Life history interviewing is a commonly used technique in qualitative inquiry to do so (Massey 1990: 19; Halfacree and Boyle 1993). ${ }^{12}$ Life histories are told with a constant reference to change (Thompson 1982: 289-306) and "the life history reveals, like nothing else can, the subjective realm" (Plummer 2001: 20).

In particular, life history interviews were conducted in 2015 with 75 purposively selected migrants from the Kagera Health and Development Survey (KHDS). While not statistically representative as such of the migrant population, this information base enabled us to identify and obtain detailed and contextualized migrant trajectories and to describe the experiences of these pathways as well as their potential for future trajectories at each point in time ("the

\footnotetext{
${ }^{12}$ One of the oldest and most known life histories in social science research precisely deals with the topic of migration, namely the story of a man migrating from a rural village in Poland to the city of Chicago in the United States (Thomas and Znanieki, 1918; 1958).
} 
potentiality of the present, projected in the future" in the words of Bjarnesen (2009), all from the migrant perspective.

The baseline KHDS, conducted over several rounds during 1991-94, contains data on 6353 individuals, living in a representative sample of 915 households in 52 villages in rural Kagera, a province in north-western Tanzania. After their first interview, the households were resurveyed in 2004, and again in 2010. A unique feature of the survey is that it also tracks all individuals who had left their baseline locations to migrate to other rural areas, smaller secondary towns or larger cities. The availability of this longrunning panel data is exploited to maximize the diversity in migration experiences in our sample, while minimizing the diversity in characteristics at the outset.

To do so, the 2010 survey data was first used to map migration patterns of all 52 villages. Out of these, 6 villages were purposively selected, based on their livelihood systems and socioeconomic profiles during 1991-94 as well as their geographic location. In August 2015, these villages were visited to update the whereabouts of all respondents originating from them. From this updated list, we identified all KHDS respondents who were approximately 15-25 years old during the 1991-94 baseline and had moved to (1) Dar es Salaam, a mega-city of 4.5m people, 1,650 km away on the Indian Ocean; (2) Mwanza, Tanzania's second largest city with a population of about 700,000 , located on the southern shores of Lake Victoria, about $450 \mathrm{~km}$ away; (3) Bukoba, Kagera's regional capital, with a population of about 100,000 and close by for most; (4) a range of much smaller rural towns in the Kagera region ${ }^{13}$ and (5) those who migrated to towns and/or cities at some point in our 23 year study window, but were found residing back home by 2015 (return migrants). ${ }^{14}$ This yielded a total of 87 individuals, 75 of which were interviewed. The remaining 12 could either not be traced or declined to be part of the study. ${ }^{15}$

The destinations of the migrants originating from the different villages are in Table 1. With villages $\mathrm{A}$ and $\mathrm{B}, \mathrm{C}$ and $\mathrm{D}, \mathrm{E}$ and $\mathrm{F}$ each geographically close to each other and very similar in terms of livelihood systems and socio economic profiles at the baseline in 1991-94, it

\footnotetext{
${ }^{13}$ These are Mutukula, Bunazi and Katoro. Mutukula, is an official border post town with a population of about 5000, where many of the cross-border traffic stops to clear custom and immigration. Bunazi, with a population of 5000 at the last census, was nothing more than a village till it recently got designated as regional capital, which triggered growth. Katoro, only has a population of 2,500 , according to the 2012 census, but is a vibrant rural trading town, many shops and traders. The early origins and urban growth dynamics of one of these towns, Katoro, is examined in-depth by Bryceson (2011). A similar examination of the interdependency of rural villages and a small town in the Kagera region is Jonathan Baker's (1995) case study on Biharamulo.

${ }^{14}$ Return migration in the KHDS sample is described in detail in Hirvonen and Bie-Lilleor (2015).

${ }^{15}$ This is a high rate of success in tracking, made possible by the judicious efforts and experience of the KDHS team to track migrants in the previous survey rounds. Migrants were traced through the use of addresses, cell phone numbers, and detailed instructions on how to reach them at destination. Where this information could not be obtained at the baseline village, it was sought in other places, for example with relatives of the migrant whose contact details were known.
} 
becomes clear how quite different migration patterns can emerge from rather comparable initial settings. While village A saw several of its youngsters migrate to the city, neighboring village B barely experienced any outmigration at all. Likewise, while the intensity of outmigration was similar in in village $\mathrm{E}$ and $\mathrm{F}$ (18 and 14 of the interviewees were respectively residing outside the village), migrants of village $\mathrm{E}$ were more likely to be found in the larger urban areas (city and Bukoba), while migration out of village $\mathrm{F}$ had been oriented more to destinations nearby (neighboring towns and Bukoba).

Table 1: Number of respondents by origin and final destination in 2015

\begin{tabular}{ccccccc}
\hline $\begin{array}{c}\text { Origin } \\
\text { village }\end{array}$ & Dar & Mwanza & Bukoba & $\begin{array}{c}\text { Small } \\
\text { Town* }\end{array}$ & Return & TOTAL \\
\hline A & 10 & 12 & 5 & 1 & 1 & $\mathbf{2 9}$ \\
B & 2 & 0 & 0 & 1 & 0 & $\mathbf{3}$ \\
C & 1 & 2 & 0 & 1 & 0 & $\mathbf{4}$ \\
D & 0 & 0 & 4 & 1 & 2 & $\mathbf{7}$ \\
E & 3 & 4 & 10 & 0 & 1 & $\mathbf{1 8}$ \\
F & 2 & 0 & 4 & 7 & 1 & $\mathbf{1 4}$ \\
\hline TOTAL & $\mathbf{1 8}$ & $\mathbf{1 8}$ & $\mathbf{2 3}$ & $\mathbf{1 1}$ & $\mathbf{5}$ & $\mathbf{7 5}$ \\
\hline * Mutukula, Bunazi and Katoro & & & & &
\end{tabular}

Twelve focus group discussions, were further conducted in the villages of origin, each time with men and women separately, typically with about 8 participants per focus group. Twelve interviews were also conducted with prospective migrants, identified by others in the village as considering migration.

Semi-structured interview guides with broad open ended questions were used to gather demographic information as well as detailed information on all acts of migration and occupations over the past two decades and a half. In addition, respondents were asked to evaluate their lives over time, related to the places where they lived and the activities they undertook to make a living. The interviews also inquired about their (changing) links with the places of origin over time, their perceptions of the places where they resided and their projects for the future, in general and with respect to migration and ways of making a living. Importantly, the interview procedure systematically probed for the factors that informed their choices (to migrate) and options they considered but did not pursue. In doing so, we followed approaches that aim to engage migrants into deliberate reflection on their intentions and choices to migrate in a changing environment (Findlay and Li, 1997: 37). 
All interviews were recorded in the local language and translated in English. The interviews were examined through a narrative analysis and a causation coding approach. ${ }^{16}$ For the analysis, we systematically considered: (1) the actual migration patterns; (2) the self-reported reasons determining the choice of destination; (3) the reasons whether and why other locations where considered but not chosen; (4) alternative destination locations considered but not taken and why not; (5) assessment of 'quality of life' in case one would be migrating to other locations (cities or secondary towns), why such an assessment is made and, in case of a better 'quality of life' in other destinations, why one does not migrate to that location; (6) the changing relationship with the village of origin over time and, in general, (7) prospects for the future.

\section{A Migrant's Tale}

To better appreciate the dynamic nature and complexity of the migration process, and thus the importance of considering the full migration trajectory for understanding the migration and location choices as they unfold, we begin by recounting the life history of Raymond as it was related to us. ${ }^{17}$ It also helps bring migration to life, giving a flavor of the nature and richness of information and insights obtained through our life histories.

Raymond was 15 years old when his father died. In his will his father had instructed the house and half of the family farm to go to Raymond, once he would have grown old enough to take proper care of them. But, like many local boys, Raymond was attracted by life outside his home village. Dar es Salaam, Tanzania's commercial capital with 4.5m inhabitants and 1,650 $\mathrm{km}$ away from Raymond's village, stood out for him as a destination: "People say Arusha is a city, but Dar is something else. There used to be video shows in our village and all the famous football players, like Runyamila, seemed to live in Dar. We were childish at the time and we thought that if we went to Dar we'd see all these people."

Raymond was not sure that he was street smart enough to survive in Dar. Having spent all his life in his home village, speaking mainly Haya, he worried about how his knowledge of the national language (Swahili), about his level of education and about his lack of exposure. Besides, he would never be able to afford the fare to Dar, USD 50 one-way at the time, a huge amount given the limited opportunities to earn cash in the village, especially for a youngster like himself, and he did not have anyone who could host him temporarily upon arrival.

\footnotetext{
${ }^{16}$ For this we used Nvivo, a qualitative data analysis software.

${ }^{17}$ Interview Kazinga, rural village, 29 September 2015. For confidentiality purposes, fictive names are used.
} 
Dar being outside of his league, some of the other obvious urban options for Raymond were Mwanza $(700,000$ people, $435 \mathrm{~km}$ away, one-way fare of USD 12) or Bukoba $(100,000$ people, $50 \mathrm{~km}$ away, one-way fare USD 2). Bukoba was not only physically a much closer location, but also more familiar. Even though Bukoba had a mix of people from all over Tanzania, many of them had backgrounds Raymond could more easily relate to. And while Swahili was the lingua franca, Haya could be heard everywhere on the street.

By the time he was 19 years old he had saved up USD 10, earned primarily through farming tomatoes and fishing in a small lake close to his village. This was enough to cover the fare to reach Bukoba and he also knew a person who could host him for a while. He also had a goal. He had always been fascinated by cars and had heard that the Lake Zone Driving School taught young men how to drive. So, he set off to Bukoba with the aim of becoming a driver.

But driving school cost money, so his first priority upon arrival was to get some form of employment. He went into shops asking whether there was any work to be done and got an interesting proposition from one shopkeeper whose shop had a veranda adjacent to the bus stand. He would receive wholesale quantities of sugar, soap, rice, sweets, chewing gum and other goods on loan and sell them on in smaller retail quantities outside the shop, with a small mark-up. Many of his customers were locals travelling to and from the nearby villages. The deal was that after he'd finished selling a batch he would pay the wholesale price to the shopkeeper and pocket the difference. It took him a month to get set up in his own place and a year to save up enough money to go to driving school.

Not long after completing driving school, the local authorities started cracking down on hawking and street trade. Villagers who were considered to be loitering about, were sent home heavy-handedly. With his obvious rural origins, Raymond did not feel secure anymore in Bukoba and his income, which derived from an activity upon which the government now frowned, became unstable. He wanted to get out of Bukoba quickly and going back home, "where you can always eat bananas for free", was his best option. Returning back after a month, he tried to pick up his business but found that other players had moved in and the prices he needed to sell at, were being undercut by bigger players with more capital.

He was then 20 years old, but much had changed in the past year and a half. The job he did metaphorically describes the conduit he had been between his rural customers and the urban goods he sold them. Raymond had been in a familiar environment in Bukoba, but he had also been exposed to people from all over Tanzania and now spoke Swahili with confidence. All 
the while the free bananas from the village had only been $50 \mathrm{~km}$ away, a distance he could cover by bus for USD 2, or, for a young man like Raymond, even on foot if he had really hit rock-bottom. He had also built up contacts with people who had ventured further out, travelers who had been to Kampala (capital of neighboring Uganda), Mwanza and Dar es Salaam.

One of those people had told him about an employment opportunity off-loading trucks and boats in a fish exporting factory on the shores of Lake Victoria. Raymond decided to take up the invitation, partly because his friend had told him he could host him for a while. He sold off his belongings in Bukoba for USD 35 and with that money bought a USD 12 one-way ferry ticket to Mwanza.

From there Raymond's life story continued. It was narrated to us in 3:15 hours of taped interview and transcribed onto 75 pages of text. Between 1997 and 2015 he made 8 moves in total and with every move his finances, networks, urban savviness and professional skills all shift and slide; and with them also the set of future opportunities he can plausibly take advantage of. In sum, through every move he made Raymond gradually expanded his action space, i.e. the range of possible destinations he could travel to as well as the different ways of making a living at his disposal. Secondary towns like Bukoba played a crucial role in this process. It is the urban environment where his aspirations and resources were built and adjusted.

While he never became a driver, he did fulfill his dream of going to Dar. He never found anyone to host him there, but having gathered (just) enough money for the fare, he felt confident enough to simply head out there and try his luck. He spent 8 years in Dar sorting scrap metal, running errands on a tricycle for a restaurant, supervising workers on a construction site, feeding lions and tigers at a zoo and, finally, as a security guard and invigilator at a school.

We met him in 2015 in his home village, where he now farms and rents out fishing equipment. In 2014 he returned home to secure his claims on the land his father left him. During his absence his mother had allocated it to Raymond's younger half-brother, whom she had with another man after Raymond's father had passed away. Having been away for so long, Raymond had to put up a fight, but things are settled now. He has two children, but they do not live with him. Perhaps the lack of such ties is why he says he could leave again if an interesting opportunity arises. 


\section{Action Space and Cumulative Causation}

The story of Raymond illustrates the critical notion of an action space and how it changes over time, through a process of cumulative causation. The notions of action space and cumulative causation also resonate throughout our respondents' life histories and migration trajectories. They prove powerful concepts in helping interpret and organize the insights from the migration narratives. At any point in time, each migrant is considered to have a certain action space. ${ }^{18}$ It defines the maneuvering room open to the migrant and is largely shaped by a person's aspirations, the resources available to him, as well as the reigning social norms (as explained in detail in section 6). The action space defines the range of possible destinations a migrant can realistically move to and, intimately linked to this, the set of possible livelihoods at destination.

But, a person's action space is not static, and the very act of migrating alters (and at times also deliberately serves to alter) the action space itself, inducing a process of cumulative causation. The importance of cumulative causation in understanding migration is not new. It was introduced as early as 1957 by Myrdal and later built upon by Massey (1990) and others in the context of migration. In Myrdal's words (1957):

"Not only are individual decisions dependent upon contextual factors, but decisions taken at one point in time have profound impacts on the context for decisions made at later dates. Migrants make choices based on their personal characteristics, preferences, and constraints imposed by the immediate socioeconomic environment; but over time these decisions feedback on structures within the environment (i.e., social networks) to change them in ways that encourage further migration, inducing others to migrate, whose departure, in turn, affects structural conditions further, resulting in a complex process of "circular and cumulative causation [...]."

Beyond cumulative causation and feedback loops on the structures affecting migration, such as the development of migration networks or changing reigning norms and habits, there is also a cumulative effect of migrating on the agentive side. As migrants migrate, they can update their aspirations, resources, personal networks, thereby each time also changing their action space.

\footnotetext{
${ }^{18}$ We develop our own meaning of the notion of 'action space', originally coined in Wolpert (1965).
} 
The importance of the notion of action space, the different forms of cumulative causation and their interplay in understanding the migration process will be further illustrated through our migrants' narratives in the sections below. They also prove critical in appreciating the role of secondary towns. To set the stage, we first explore the concept of rural and urban from the migrant's perspective.

\section{Urban from the Migrant Perspective}

Whereas experts define urban locations based on the size and density of the population or on administrative divisions determined by government officials (Christiaensen and Kanbur, 2017), it is insightful to take a migrant perspective - such as Raymond's - on the definition of what is urban and what distinguishes different urban locations from each other. Three main characteristics emerge that typify the urban environment for migrants: vibrancy, monetary exchange and anonymity.

The first identifying element, vibrancy, was most frequently expressed by the Swahili notion of "mzunguko wa pesa", which literally means the circulation of money and the abundance of transactions between buyers and sellers. In the broadest sense, it refers to the vibrancy of a particular place in terms of the circulation of goods, people and ideas. Migrants are initially attracted by a general sense that some potential destination has a high mzunguko wa pesa, not so much by concrete information on jobs or price differences. When we asked Sediki, who is currently living in a small urban center in Kagera, why his life would be better in Mwanza he told us: "honestly, Mwanza is also a good place, because on TV you can clearly see that everyone is busy working there". ${ }^{19}$ The higher the perceived movement, circulation, energy or density; the higher the expectation to be able to make a living irrespective of concrete information and connections.

A second identifying element is the monetized nature of transactions. Money mediates most transactions and, compared to village life, much less is obtained for free or through reciprocity or barter. Raymond returned to his village when things turned ugly in town, because that was where he "could eat bananas for free". Another example comes from Thaddeus, who migrated to four different places: a small town, two cities (Musoma and Mwanza) and eventually the capital Dar, where he currently lives. He recounts his experience of moving into an urban environment as follows: "It was difficult life. I was used to free

\footnotetext{
${ }^{19}$ Interview Bunazi, secondary town, 9 October 2015.
} 
cassava and fruits in the village but in town everything was for sale. At first, this kind of life was hard, but now I'm used to it and find it normal.,"20

Like many other respondents, both Thaddeus and Raymond touch on an important element of urban life: migrants need to learn how to operate in a much more monetized environment. The inability, or fear of being unable to navigate the cash economy is one of the barriers to migration. It also explains the importance of having relatives at destination. Secondary towns have a facilitating role to play here, especially during the first move. Not only is it more likely to have relatives near to secondary towns to help navigate the cash economy, they also hold the middle ground between the reciprocal village economy and monetized city life, reducing the imperative for cash.

The third identifying element is anonymity. Perhaps surprisingly, anonymity is often seen as a good thing. Take our conversation with Hector, for example:

(Interviewer) So you could make a good living for yourself in Dar es Salaam?

(Respondent) In Dar es Salaam any kind of business will flourish.

(Interviewer) Why does it thrive in Dar es Salaam and not here in Bukoba?

(Respondent) Take selling drinking water in the street, for example. Who would you sell water to in Bukoba? But in Dar es Salaam people do this kind of business without shame. They do what they came for.

(Interviewer) So you would feel ashamed doing this near home?

(Respondent) Yes, and even if you were to start selling it no one will buy here, because we have a lot of free water.

(Interviewer) So you don't feel ashamed to do anything because it is far from home?

(Respondent) Yes.

(Interviewer) Meaning you can do anything to earn you a living?

(Respondent) Yes. ${ }^{21}$

The lack of anonymity in the village environment is a two-edged sword, however. On the one hand, exactly because of the more intense personal relationships, the home village often provides an important safety net and refuge for those who are down on their luck during a move. On the other hand, it is often experienced as a suffocating and stifling environment. Beate's life story is a case in point. ${ }^{22}$ In the year 2000, she moved from a village into Bukoba, where she got married in 2007. She and her husband were making a living off a small kiosk.

\footnotetext{
${ }^{20}$ Interview Bukoba, secondary town, 6 October 2015.

${ }^{21}$ Interview Bukoba, secondary town, 10 October 2015.

${ }^{22}$ Systematic quantitative analysis by De Weerdt and Hirvonen (2015) points in the same direction.
} 
But when her husband fell sick three years later, they had to sell off the shop. Stripped of their income source and without any assets, they returned to the village on foot. There they worked on the family farm for five years. By 2015, her husband's health had gotten better and the family returned to Bukoba - a place they had become familiar with in the meantime. It was especially the relationship with her family-in-law that pushed them to return to town. Her inlaws were tying Beate down. In her own words:

"Any time I left the village my father-in-law would harvest bananas from my farm. He'd be continually back-biting me, telling everyone that I don't give him anything. He tells his [other] son that I steal beans from him and sell them. In my eyes life in the village is very low. But in town you can set yourself up like you want to and live your own life. And then life can be good. You could do your own thing in the village too, but even if you are given money to set up a business it will never thrive. People won't buy anything and there is so much hypocrisy in the village. But in town everyone is on their own and no one cares about anyone else's life."

The most vibrant, monetized and anonymous location in Tanzania is, by far, Dar es Salaam, which with a population of 4.5 million dwarfs the second biggest city Mwanza of 700,000 inhabitants. Dar es Salaam is also a brand and young boys like Raymond associate it with the glamorous life of football and movie stars. But only very few respondents have a clear plan on how to reach its bright city lights.

\section{Components shaping a migrant's action space}

Together the 75 migrants we interviewed made 208 moves in total over the past two decades, with the first destination also being the final destination for only 36 percent, while almost half of them stayed in three or more places during 1991-2015 (Figure 1). Clearly, for many, migrating is not a one-time act, but rather a dynamic, cumulative process.

Figure 1: Most migrants make several moves. 


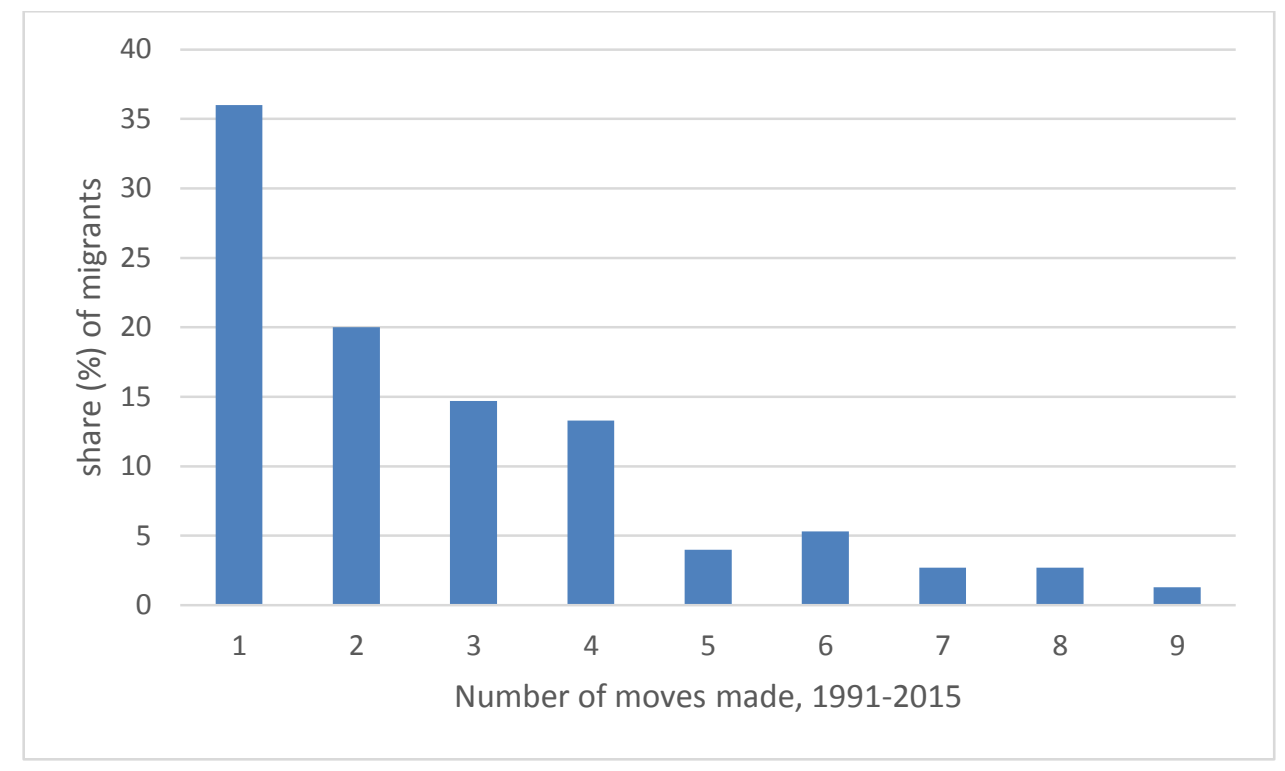

To help organize the factors shaping action space over time, as recounted to us through the migrant narratives, we draw on the notion of human agency (Emirbayer \& Mische 1998). The different components of human agency, although closely entangled empirically, can be grouped into a projective, a practical-evaluative and iterative component. In this view, the act of migrating thus consists of an aspirational component that is forward looking (imagination), which finds concrete operationalization through a practical-evaluative component (individual judgement) that is further shaped by habits and social norms often inducing people to follow established routines (iteration). This broadly resonates with the patterns observed in the life histories.

\subsection{The projective component: aspirations}

A principal component of human agency is the projective component, which constitutes "the imaginative generation by actors of possible future trajectories of action, in which received structures of thought and action may be creatively reconfigured in relation to actors' hopes, fears, and desires for the future" (Emirbayer \& Mische 1998: 971). This aspect of human agency is closely related to what Appadurai (2004) has called the 'capacity to aspire'. Aspiration allows people to travel paths that, if one only takes their resources into account, they would normally not take.

The importance of aspirations in understanding migration and location decisions is an important undercurrent throughout the different life histories, as exemplified by the histories 
of Hector and Sophie. ${ }^{23}$ Both originate from the same village ${ }^{24}$ and have similar socioeconomic backgrounds. Both also experienced urban life in smaller towns around their village and were savvy enough to navigate these local urban environments. Both had the means and networks to move to Dar es Salaam, the country's economic capital, more than $1000 \mathrm{~km}$ away. But, while Sophie went to Dar es Salaam, Hector took up residence in Bukoba. Why?

When asked about their dreams for the future, Hector responds: "Which dreams?". Sophie, by contrast, has very concrete dreams of starting her own business, being her own boss and providing a good education for her children. When asked whether she'll be able to achieve those dreams, the answer was an emphatic "yes". When asked how, she said: "My plan is to have my own business in two or three years. I am sure that if I work hard in my own business, I will achieve my dreams. What matters is perseverance and working very hard." Hector, on the other hand, is much more fatalistic about the contribution of his own efforts in shaping his future.

God is universally invoked by respondents describing future plans. But it ranges from the more fatalistic and conditional "if God wishes", to stressing how, through their own hard work, they will realize their goals "by the grace of God". The projective component of human agency fuels migration and results in the resolve needed to overcome constraints and to challenge or circumvent social norms. It is a first explanation why the horizon of some migrants stretches towards far-away cities, whereas others never aspire to move beyond an urban environment that is close-by. Although Hector probably could travel outside the Kagera region, he does not aspire to do so. He is satisfied with where life brought him. At the time of the interview, there was no indication that Hector had the intention to expand his action space, precisely due to the fact that he seemed satisfied with his achievements in life brought to him by the urban environment of a secondary town. Like Hector, many of our study participants do not aspire to move further than a secondary town.

\subsection{The practical-evaluative component: gathering resources and adapting to the cash economy}

In addition to the projective component of human agency, Emirbayer \& Mische (1998: 971) further distinguish the practical-evaluative element, i.e. "the capacity of actors to make

\footnotetext{
${ }^{23}$ Hector: interview Bukoba, secondary town, 10 October 2015; Sophie: interview Dar, capital city, 31 October 2015

${ }^{24}$ Many factors shape people's aspirations, including the existence of migration networks in the village, and relatedly its past migration history. To begin to explore the potential role of aspirations in migration and destination decisions, one should thus, at a minimum, compare life histories and destination choices of migrants of the same village.
} 
practical and normative judgements among alternative possible trajectories of action, in response to the demands, dilemmas, and ambiguities of presently evolving situations". This dimension entails the actual decision-making to achieve the broader goal of migrating. ${ }^{25}$ Throughout the migration histories, the focus herein was mainly on the type of resources and other capacities needed to migrate, as such, but also in relation to particular places, nearby towns or faraway cities.

Overall, the need for money for the fare, a network at the destination to get set up, the ability to function in a cash economy and the professional skills needed to obtain meaningful employment are most frequently mentioned by the migrants. They affect the financial ability to cover the cost of migration and settle safely in the destination as well as the likelihood of success in finding a job and developing a livelihood once there.

Having the money to pay the fare and having a host to support you upon arrival are the two most commonly mentioned resources that define whether you can enter an urban environment and what kind of urban environment you can enter. Take Eric. He explained how he only considered Dar es Salaam as an option because "I had my relatives in Dar es Salaam, so I could be helped in case of any problem." ${ }^{26}$ Christopher indicated: "No, I did not think of going to any other place apart from going where I knew that my relatives were and that I was not going to suffer." Similarly, Layla, also currently in Dar es Salaam, would not consider a move to Mwanza, but does not exclude setting up in smaller towns in Kagera: "[In Mwanza] I would be new in the city and have nowhere to start from. I have no friends or relatives there. Despite the opportunities for employment and businesses I have no one to guide and support me. [...] I have many friends and relatives [in Bukoba and other small towns in the Kagera region] who could assist me in finding a job or starting a business". ${ }^{27}$

The critical importance of pre-existing migration networks in determining the act and destination of migration is confirmed here and has been well established, especially with respect to international migration (Boyd, 1989; Gurak and Caces, 1992; McKenzie and Rapoport, 2007). Equally salient in our life histories, however, and arguably less appreciated, is the importance of liquidity or cash constraints, especially to cover the cost of migration, i.e. to pay the fare. Time and time again people talked about how they are "still gathering the

\footnotetext{
${ }^{25}$ In some instances the deliberation is systematic and optimizing, but it doesn't have to be, as is often the case with the first move, which is more about satisficing (Simon, 1952). It typically also depends on personal pre-dispositions, such as a person's disposition to risk and entrepreneurship.

${ }^{26}$ Interview Dar, capital city, 21 October 2015

${ }^{27}$ Interview Dar, capital city, 1 November 2015
} 
fare" or about money more generally "how can I move to Dar es Salaam without money?"28 Against this background, the finding from a recent randomized experiment in Bangladesh where a US\$ 8.5 incentive (covering round-trip travel costs) induced a noticeable increase in seasonal migration to off-farm jobs in nearby towns, does not surprise (Bryan, Chowdhury, Mobarak, 2014).

Thirdly, most migrants decide to build up their skills while migrating and building up the professional skills is a key first step at destination. Physical and socio-economic mobility are closely connected. At times, it happens through formal learning, but mostly through learning on the job. A first step towards learning about masonry, for example, is to carry bricks around on a construction site and to seize the opportunities it provides to learn about other house building skills. Or take the example of Raymond again. As a young man, he used to fish in a small lake near his home village. When he pushed on to Mwanza from Bukoba, he took up a job in a fish factory. Here, he further developed his knowledge of and networks in the fish sector, which shaped his future employment trajectory: (i) working on a boat that transports fish, (ii) being a middleman buying from fishermen and selling to a small factory and (iii) working on a boat ferrying passengers around the fishing islands of Lake Victoria.

Many life histories share this pattern in which the migrant's professional skills (and his/her sector specific networks), and thus the action space, are formed and expanded through migration and cumulative causation. ${ }^{29}$ But, as explained above, finding one's way in the anonymous and money driven urban environment is not straightforward. This makes the first move and destination choice, when resources are limited and knowledge and familiarity with the outside world still uncertain, also peculiar. Getting out becomes important in itself. It provides opportunities to expand one's action space. It helps shake things up and break the vicious circle of not having the necessary resources, networks or skills to move and/or find employment, while the acquisition of these is in fact facilitated by moving itself, even if it only entails one move.

Secondary towns prove instrumental in initiating such first moves for several reasons. As they are nearby, less cash is needed to finance the move (or to return in case of failure). This increases the likelihood of other villagers having trodden the path and thus the likelihood of pre-existing networks, which in turn lowers the barriers to a first move and success at

\footnotetext{
${ }^{28}$ Interview Bukoba, secondary town, 7 October 2015.

${ }^{29}$ Less frequently migrants go searching for demand for their skills. An example is Andy, who we interviewed in Bukoba on 6 October 2015. He had studied welding at school, but there was no demand for welders in his own region. He moved to Tabora, a secondary town in the center of the country, where he got a job with a construction company for four years.
} 
destination. With exchange relations in secondary towns holding a middle ground between subsistence agriculture in the village and the anonymous monetary relations in the big city, they are also easier to navigate.

\subsection{The iterative component: Norms, habits and path dependency}

The iterative element of human agency refers to "the selective reactivation by actors of past patterns of thought and action, as routinely incorporated in practical activity, thereby giving stability and order to social universes and helping to sustain identities, interactions, and institutions over time" (Emirbayer \& Mische 1998: 971). This dimension of human agency relates physical mobility to custom, habit, established ideas, norms and socially sanctioned ways of acting.

Age and gender are important here. Migrating out of the village in order 'to look for life' (kutafuta maisha in Swahili), seems to be a socially sanctioned practice for many young boys coming of age. But our histories also show that as families are formed, people age, and habits set in, the appetite for adventure and the propensity to migrate usually declines, thereby defining a window of opportunity for migration that is closely linked to the lifecycle. Available studies on internal migration in Tanzania also show that most migrants are young (Msigwa \& Mbongo 2013: 32).

When it comes to gender, women in Kagera were in fact found to migrate more than men ${ }^{30}$, though they often travel differently and for different reasons. First, they migrate more because of marriage, especially when moving in rural areas. Marriage is patrilocal, so women will move to the village of the husband or to another location. It is unheard of that the man would live in the woman's village. When they move for economic reasons, which is also not uncommon, the destination specificity and awareness of the circumstances in the place of destination is also much more accurate. Whereas (young) men tend to migrate out of agriculture based on general stories of opportunity in certain places, (young) women have a more precise view of their trajectory and the conditions upon arrival. Namwezi, for instance, was much more guided by family members in her decisions on why and where to migrate when she first travelled from her village to Mwanza in 2003 and, later on, to Dar es Salaam in 2009. She knew that she was going to be able to attend a tailoring course and live with her aunt before she left the farm. Her subsequent move towards Dar was facilitated and

\footnotetext{
${ }^{30}$ According to KHDS, by $2010,59 \%$ of interviewed men were found in the same village compared with $46 \%$ of women.
} 
supervised by her uncle. ${ }^{31}$ Men and women's action space is shaped differently through gendered norms.

The specific place where one grows up is also important. Although our study villages are all similar and close to each other, micro-cultures of migration seem to have taken root. They shape ideas on the value of mobility and the trajectories taken. For example, village A has many more migrants moving into urban areas, while migrants in the neighboring village, village $\mathrm{B}$, tend to travel to other agricultural areas or fishing villages. A boy coming of age in village $A$ is likely to aspire to the urban lifestyle, whereas a similar boy in village $B$ will have a much more rural outlook, even though both villages are socio-economically very similar and physically close.

Probing for the reason behind this localized path dependency in focus group discussions in villages $\mathrm{A}$ and $\mathrm{B}$, participants pointed to the lasting effects of pioneer migrants. During colonial times and with the help of missionaries, a few people in village A achieved quite high education levels and made careers for themselves in urban areas, outside of agriculture. This set in motion a series of feedback loops with the village, which changed the structural conditions under which mobility takes place. The pioneer migrants were the beginning of a network that connected village A with the city of Dar es Salaam. At the same time, they influenced how people started to think about what constitutes a good life, how to reach it and who the relevant role models were to which life should be compared. This dynamic also exists in a place like village B but has taken a different form with mobility patterns that are not geared towards urban environments.

\section{Why do more migrants end up in secondary towns?}

What do these rich contextual insights about the conception of the urban space and the drivers of migration tell us about the role of secondary towns in migration and poverty reduction (at least in an accounting sense)? On the one hand, the city clearly has the greatest appeal. Seen from the village, it is the most vibrant, offering the most opportunities. It is where the money really circulates. This holds in our case study, and resonates with what has been observed in the rest of the world. It is also consistent with the observed income gradient declining from city over town to village and thus the larger income gap between Dar es Salaam and rural Kagera compared with secondary towns.

\footnotetext{
${ }^{31}$ Interview Dar, capital city, 22 October 2015
} 
Yet, for the rural population in Kagera, the city also proved much harder to reach, especially in the absence of any pre-existing migration network, to help with the bus fare, settling costs and job search. Secondary towns are more likely to find themselves within the migrants' action space for several reasons, initially, at the moment of the first move, but also later on, as the migration trajectory unfolds. The life histories show how initial migration out of rural areas is primarily motivated by the desire "to look for life" outside of agriculture. Yet, few have the practical means to move from a tightly-knit, traditional rural community straight to the anonymous cash-based city.

Secondary towns emerge as the more feasible urban destinations, as they are both physically and culturally more accessible. They occupy a unique space in between rural livelihoods, based on home production and reciprocity, and the capitalist city economy based on monetary exchange. They are also less costly to reach and, as a result, migration networks are also more likely to have established, further reducing the cost of migration and settling. Their proximity also facilitates information flows about employment opportunities. According to the KHDS, one in three town migrants, for example, already had information about a job prior to moving, compared with only one in six among city migrants, with the job information more frequently obtained through relatives and friends among town migrants. ${ }^{32}$ Lack of information about employment opportunities and familiarity with the destination tends to pose an even larger barrier for households close to subsistence, for whom experimenting with a new activity imposes a bigger risk (Bryan, Chowhury, Mobarak, 2014; De Weerdt and Hirvonen, 2015). ${ }^{33}$

By facilitating the first move, secondary towns can further expand the migrant's action space, and induce a process of cumulative causation and a virtuous circle of migration and livelihood diversification. The very act of migrating changes the conditions that were previously so constraining. The migrant's financial situation changes, s/he obtains skills, forges new connections and the exposure to life outside the village changes the life they aspire to lead and, for some, builds confidence to move on further. Secondary towns, in short, can expand the horizons of rural dwellers, both for those who transit through them as well as for those who end up living there. In the longer run they also alter the social and economic structures of the villages these migrants originate from, as emphasized by de Haas (2010). Gradually, links between these rural locations and the urban areas can become stronger, lifting villages out of

\footnotetext{
${ }^{32}$ From the KDHS data, secondary town migrants with information about a job obtained it mostly from the employer personally (34 percent), relatives and friends ( 27 percent), and word of mouth (15 percent). City migrants relied more on the employer (44 percent) and word of mouth (20 percent), with only 12 percent of them obtaining info from relatives and friends.

${ }^{33}$ As such, households less likely to have pre-existing network connections at the destination were found to be more responsive to the seasonal migration incentive (free return bus ticket) (Bryan, Chowdury, and Mobarak, 2014). They also exhibited greater learning about migration opportunities and destinations in their subsequent choices on whether and were to re-migrate.
} 
isolation. And future migrants are not only inspired by local examples, they now also have the necessary networks to make the move happen in practice.

To be sure, as the histories make clear, not all moves are immediately (or eventually) successful. This also holds for moves to towns. Many migrants undertake multiple moves and with every move the migrant's set of future opportunities - her action space - changes, either expanding, remaining unchanged, and at times also contracting. As such we distinguished one-directional moves (to the city or town), ladder migration (from village to town to city), churning (a continuing quest to search one's luck across destinations) and return movement to the area of origin. ${ }^{34}$ As highlighted above, the migration process does also not go on forever. It happens within a lifecycle related window of opportunity within which most migration and location decisions are taken.

An exercise conducted with all respondents was to rank alternative destinations over their current location in terms of having a good life (expressed on a ladder of life). If some other destination was ranked above where they were at the time of the interview, we probed why they were not moving there. Hanani, who currently lives in Dar es Salaam believes that his life would be better in Mwanza and when asked why he does not move there, answers "It is impossible because right now I live in Dar es Salaam. Going to Mwanza means that I will begin from square one." 35 Jameson, who currently lives in a secondary town in Kagera, believes he would be better off in Dar es Salaam. When asked, what is preventing him from moving, he says:

(Respondent) I now have a big family. I cannot neglect them; it is not like before.

(Interviewer) Why did you not go there when you had no family?

(Respondent) I didn't think of it.

(Interviewer) You never thought of it?

(Respondent) Well, let's say I didn't have the fare to get there. ${ }^{36}$

As migrants become increasingly invested in work, set up families and develop social ties, they eventually settle down. For many this happens after the first move, others do so later in the process. Whereas proximity explains why secondary towns are part of the early action space of many rural dwellers, it is the process of gradually increasing inertia as migrants proceed in their life cycle, which explains why many more also settle in towns, because that's

\footnotetext{
${ }^{34}$ A detailed analysis of the determinants of the trajectory prospects at the outset falls beyond the scope of this paper.

${ }^{35}$ Interview Dar, capital city, 19 October 2015.

${ }^{36}$ Interview Mutukula, secondary town, 8 October 2015.
} 
where they often find themselves. And whereas this is an important dynamic to take into account for those wanting to move to the city, we should not forget that many others do not aspire to move beyond a secondary town in the first place, as the life story of Hector discussed above shows.

\section{Concluding remarks}

This paper analyzed the recorded narratives of the life histories of 75 purposively sampled migrants from rural Kagera, a remote region in northwestern Tanzania to better understand why so many more migrants end up in secondary towns, despite objectively larger welfare gains among those who end up in the cities. Following insights emerge.

First, migration emerges as a highly dynamic process, best understood through the notion of an evolving action space, which at each time determines the range of destinations and livelihood opportunities, and cumulative causation, whereby the migration process itself alters the action space over time as migrants move from one place to the other. This stands in contrast to the more prevalent static view of migration as a one-shot event that governs economic modeling and policy making. A more dynamic and path dependent approach and longitudinal data collection efforts and analysis are called for in the study of migration and policy design. It is migration movies that are needed, not snapshots.

Second, the first move is distinctly different. It is primarily motivated by the desire to leave the village and to leave agriculture, come-what-may, "to look for life" (kutafuta maisha), a dominant theme when migrants discussed their first move. It shakes thing up, changing seemingly inalterable conditions and creating openings and opportunities where there were none before. Finding the 'good life' continues to animate the migration process also in subsequent migration instances, but now with the benefit of the experience and learning gained through the first move.

Third, proximity continues to matter in non-trivial and underappreciated ways. This was emphasized early on in the study of migration by Sjaastadt (1962) and Schwartz (1973), but the appreciation of the importance of distance in shaping migration and destination decisions has gradually faded into the background since. With secondary towns more accessible (financially) and easier to navigate, and meeting aspirations less important for the first move, they prove instrumental in opening and expanding the action space of prospective migrants, especially for those lacking pre-existing networks in the cities. This remains the reality for 
many, precisely because cities have been harder to reach and navigate successfully for previous migrants, reinforcing the importance of secondary towns to open up space for off farm employment and income diversification.

Fourth, as illustrated by migrants' and villagers' conception of 'urban', an important part of the practical appeal of secondary towns also lies in their intermediate position between the reciprocal village economy, which villagers are familiar with, and the more capitalist, monetized city life, where everything costs money. This renders them easier to navigate, while still providing a degree of anonymity to advance and sufficiently close to the home village in case things don't work out. This is despite the fact that the city undoubtedly speaks most to the imagination.

Fifth, migrants operate within a finite age-related window of opportunity for migration. As they start families and their life cycle proceeds, inertia sets in and they start to settle down. In absolute numbers, this happens mostly in secondary towns, where they often find themselves as the window of opportunity for migration starts to close.

Together these findings help contextualize the emerging body of quantitative evidence and add credence to the notion that secondary town development may be more conducive to poverty reduction than investment in big cities. With more than half of the world's extreme poor living in SSA (World Bank, 2016) and 82 percent of Africa's poor living in rural areas (Beegle et al., 2016), the findings also bear on Africa's urbanization and poverty reduction agenda. Even though the population of our case study region, Kagera, lives arguably particularly far from the economic capital, greater proximity to secondary towns than to cities is a common feature of the rural population across Sub Saharan Africa (SSA) (Food and Agriculture Organization, 2017). ${ }^{37}$ While distances can be shrunk by lowering transport costs and increasing (employment) information flows, making cities more accessible, the life histories also suggest that the challenge of moving and operating successfully in the city, especially the first time around and in the absence of a strong social network, goes well beyond the cost of the bus fare.

At 38 percent, SSA's rate of urbanization is also still relatively low. This leaves much scope for growth, which the UN projects to proceed at 1-1.3 percentage point a year over the coming two decades. ${ }^{38}$ Through the spatial allocation of investment (across towns and cities) and policy design, governments will have the opportunity to steer these new migration

\footnotetext{
${ }^{37}$ It is calculated that 22 percent of its population live within 1-3 hours from a secondary town compared with 9 percent within 1-3 hours from a city. About $1 / 3$ of the rural population lives in the rural hinterland at more than 3 hours from an urban center.

${ }^{38}$ UN World Urbanization Prospects, 2014, revision. Consulted 5 July 2017 (https://esa.un.org/unpd/wup/DataQuery/ ).
} 
streams and thus arguably, also the rate of poverty reduction. By giving a broader base of the population the ability to become physically, economically and socially mobile and access new income opportunities, secondary town development may hold a powerful policy tool for inclusive growth and poverty reduction. Nonetheless, further research is needed, both to further develop the theoretical and empirical evidence base on the role of secondary towns in poverty reduction as well as to examine the effectiveness of different policies and investments to develop these areas into vibrant and attractive centers with high "mzunguko wa pesa". 


\section{References}

Appadurai, Arjun. 2004. "The Capacity to Aspire: Culture and the Terms of Recognition", in Vijayendro Rao and Michael Walton. eds. Culture and Public Action, Stanford: Stanford University Press: 59-84.

Bakewell, Oliver. 2010. "Some Reflections on Structure and Agency in Migration Theory." Journal of Ethnic and Migration Studies. 36 (10): 1689-1708.

Bakewell, Oliver and Ayla Bonfiglio, 2013. "Moving Beyond Conflict. Re-framing Mobility in the African Great Lakes Region", Working Paper 71, International Migration Institute, University of Oxford.

Baker, Jonathan, ed. 1990. Small Town Africa. Studies in Rural-Urban Interaction. Uppsala: The Scandinavian Institute of African Studies.

Baker, Jonathan, 1995. "Survival and Accumulation Strategies at the Rural-Urban Interface in North-West Tanzania", Environment and Urbanization, 7 (1): 117-132.

Bjarnesen, Jesper. 2009. "A Mobile Life Story. Tracing Hopefulness in the Life and Dreams of a Young Ivorian Migrant", Migration Letters. 6 (2): 119-129.

Beegle, Kathleen; Joachim De Weerdt and Stefan Dercon. 2011. "Migration and Economic Mobility in Tanzania: Evidence From a Tracking Survey", Review of Economics and Statistics, 8 (1): 1010-1033.

Boyd, M., 1989, Family and Personal Networks in International Migration : Recent Developments and Agendas, International Migration Review, 23-3: 638-670.

Bryan, Gharad, Shyamal, Chowdhury, and Ahmed Mushfiq, Mobarak, 2014. "Underinvestment in a Profitable Technology: The Case of Seasonal Migration in Bangladesh." Econometrica, 82-5: 1671-1748.

Bryceson, Deborah Fahy. 2011. "Birth of a Market Town in Tanzania: Towards Narrative Studies of Urban Africa", Journal of Eastern African Studies, 5(2): 274-293.

Christiaensen, Luc and Ravi Kanbur. 2017. "Secondary towns and poverty reduction: refocusing the urbanization agenda". Annual Review of Resource Economics 9: 40519.

Christiaensen, Luc and Yasuyuki Todo. 2014. "Poverty reduction during the rural-urban transformation-the role of the missing middle". World Development, 63, 43-58.

Christiaensen, Luc, Joachim De Weerdt, and Yasuyuki Todo. 2013. "Urbanization and Poverty Reduction-The Role of Rural Diversification and Secondary Towns." Agricultural Economics, 44 (4-5): 435-447.

de Haas, Hein. 2010. "The Internal Dynamics of Migration Processes: A Theoretical Inquiry", Journal of Ethnic and Migration Studies, 36 (10): 1587-1617.

De Weerdt, Joachim, Kathleen Beegle, Helene Bie Lilleør, Stefan Dercon, Kalle Hirvonen, Martina Kirchberger, and Sofya Krutikova. 2012. "Kagera Health and Development Survey 2010: Basic Information Document." Rockwool Foundation Working Paper Series no. 46.

De Weerdt, Joachim and Kalle Hirvonen. 2015. "Risk Sharing and Internal Migration", Economic development and cultural change, 2015. Available at: https://repository.uantwerpen.be/desktop/irua/core/index.phtml?language=\&euser $=\& \mathrm{~s}$ ession $=\&$ service $=$ opacirua $\&$ robot $=\& d$ eskservice $=$ desktop $\&$ desktop $=$ irua $\&$ workstation =\&extra=loi=c:irua: 137199

Dorosh, Paul and James Thurlow. 2013. "Agriculture and Small Towns in Africa". Agricultural Economics. 44 (4-5): 449-459.

Dorosh, Paul and James Thurlow. 2014. "Can cities or towns drive African development? Economy wide analysis for Ethiopia and Uganda". World Development. 63: 113-123. 
Ellis, Frank, 1998. "Household Strategies and Rural Livelihood Diversification." Journal of Development Studies, 35-1: 1-38.

Emirbayer. Mustafa and Ann Mische. 1998. "What is Agency?", The American Journal of Sociology, 103 (4): 962-1023.

Emran, M. Shahe and Forhad Shilpi. 2017. "Beyond Dualism: Agricultural Productivity, Small Towns and Structural Change in Bangladesh." World Bank Policy Research Working Paper 8087, World Bank Group: Washington D.C.

Fafchamps, Marcel and Forhad Shilpi. 2013. "Determinants of the Choice of Migration Destination," Oxford Bulletin of Economics and Statistics. 75(3): 388-409.Food and Agriculture Organization, 2017. "State of Food and Agriculture 2017." Food and Agriculture Organization: Rome, forthcoming.

Findlay, Allan M. and F.L.N. Li. 1999. "Methodological Issues in Researching Migration". The Professional Geographer. 51 (1): 50-59.

Food and Agriculture Organization. 2017. "State of Food and Agriculture 2017." Food and Agriculture Organization: Rome, forthcoming.

Gibson, John, Gaurav, Datt, Rinku Murgai and Martin Ravallion, 2017. "For India's Rural Poor, Growing Towns Matter More than Growing Cities." i, forthcoming.

Gurak, Douglas T., and F.E. Caces, 1992, Migration Networks and the Shaping of Migration Systems in Kritz, M.M., L.L. Lim and H. Zlotnik, eds. International Migration Systems: A Global Approach. Oxford: Oxford University Press, Clarendon Press.

Halfacree Keith and Paul Boyle. 1993. "The Challenge Facing Migration Research: The Case for a Biographical Approach”, Progress in Human Geography, 17 (3): 333-348.

Henderson, Vernon and Randy Becker, 2000. "Political Economy of City Sizes and Formation", Journal of Urban Economics, 48 (3), 543-484.

Hirvonen, Kalle and Lilleor, Helene Bie. 2015. "Going Back Home: Internal Return Migration in Rural Tanzania”, World Development, 70: 186-202.

Lall, Somik, V., Harris, Selod, and Zmarak, Shalizi. 2006. "Rural-Urban Migration in Developing Countries: A Survey of Theoretical Predictions and Empirical Findings." Policy Research Working Paper 3915, World Bank: Washington D.C.

Lanjouw, Peter; Jaime Quizon and Robert Sparrow. 2001. "Non-agricultural earnings in periurban areas of Tanzania: evidence from household survey data." Food Policy, 26 (4): 385-403.

Massey, Douglas S. 1990. "Social Structure, Household Strategies, and The Cumulative Causation of Migration". Population Index. 56 (1): 3-26.

McKenzie, D., and H., Rapoport. 2007. "Network Effects and the Dynamics of Migration and Inequality: Theory and Evidence From Mexico," Journal of Development Economics, 84 (1), 1-24. [1672]

Msigwa, Robert Ebihart and James Ezekiel Mbongo. 2013. "Determinants of internal migration in Tanzania”. Journal of Economics and Sustainable Development, 4 (9), 28-35.

Myrdal, Gunnar. 1957. Rich Lands and Poor. New York: Harper and Row.

Owusu, George. 2008. "The Role of Small Towns in Regional Development and Poverty Reduction in Ghana" International Journal of Urban and Regional Research, 32 (2): 453-472.

Plummer, Ken. 2001. Documents of life 2. London: Sage.

Satterthwaite, David and Cecilia Tacoli. 2003. The urban part of rural development: the role of small and intermediate urban centres in rural and regional development and poverty reduction. Human Settlements Working Paper Series Rural-Urban Interactions and Livelihood Strategies No. 9. IIED, London. 
Schwartz, Aba. 1973. "Interpreting the Effect of Distance on Migration." Journal of Political Economy, 81-5: 1153-1169.

Simon, Herbert, A., 1956. "Rational Choice and the Structure of the Environment." Psychological Review, 63-2: 129-138. doi:10.1037/h0042769.

Sjaastad, Larry A., 1962. "The Costs and Returns to Human Migration." Journal of Political Economy, 70-5: 80-93.

Tacoli, Cecilia and Richard Mabala. 2010. "Exploring mobility and migration in the context of rural-urban linkages: why gender and generation matter." Environment and Urbanization, 22 (2): 389-395.

Thomas, William I. and Florian Znaniecki. (1918) 1958. The Polish Peasant in Europe and America. New York: Dover.

Thompson, Paul. 1982. "Life histories and the analysis of social change". In: Daniel Berteaux, ed. 1982. Biography and society. The life-history approach in the social sciences. London: Sage: 289-306.

Wolpert, Julian. 1965. "Behavioral Aspects of the Decision to Migrate." Papers of the Regional Science Association, 15 (1): 159-169.

World Bank, 2016. "Poverty and Shared Prosperity 2016. Taking on Inequality." World Bank: Washington D.C.

Young, Alwyn. 2013. "Inequality, the Urban-Rural Gap and Migration." Quarterly Journal of Economics, 128-4: 1727-1785. 